\title{
Prevalence and Correlates of Being Overweight or Obese in College
}

\author{
Brian L. Odlaug ${ }^{\mathrm{a}^{*}}$ \\ Katherine Lust ${ }^{\mathrm{b}}$ \\ Cathrine L. Wimmelmann ${ }^{\mathrm{a}}$ \\ Samuel R. Chamberlain ${ }^{c}$ \\ Erik L. Mortensen ${ }^{\mathrm{a}}$ \\ Katherine Derbyshire $^{\mathrm{d}}$ \\ Gary Christenson ${ }^{\mathrm{b}}$ \\ Jon E. Grant ${ }^{\mathrm{d}}$
}

\begin{abstract}
${ }^{a}$ Department of Public Health, Faculty of Health and Medical Sciences, University of Copenhagen, Copenhagen, Denmark

${ }^{\mathrm{b} B o y n t o n}$ Health Services, University of Minnesota, Minneapolis, MN USA

${ }^{\mathrm{c}}$ Department of Psychiatry, University of Cambridge, UK

${ }^{\mathrm{d}}$ Department of Psychiatry \& Behavioral Neuroscience, University of Chicago, Chicago IL USA
\end{abstract}

\section{*Corresponding Author:}

Brian L. Odlaug

Department of Public Health, Faculty of Health \& Medical Sciences

University of Copenhagen, Øster Farimagsgade 5, DK-1353 Copenhagen K, Denmark

Telephone Number: +45 3532 7212; Email: brod@sund.ku.dk; odlaug@gmail.com 


\begin{abstract}
Recent statistics indicate that over one-third of college students are currently overweight or obese, however, the impact of weight in this population from academic and psychiatric perspectives are not fully understood. This study sought to examine the prevalence of overweight and obesity in college students and its association with stress, mental health disorders and academic achievement. A total of 1,765 students completed the College Student Computer User Survey (CSCUS) online at a large Midwestern United States University. Responders were classified by weight as normal, overweight or obese based on Body Mass Index. Data were stratified by sex, with cross-tabulation and t-tests, one-way analysis of variance, and logistic regression for analysis. A total of 492 (27.9\%) students were overweight (20.2\%; range 25.0129.98) or obese (7.7\%; range 30.04-71.26). Overweight and obesity were associated with significantly lower overall academic achievement, more depressive symptoms, and using diet pills for weight loss. Obese males had significantly higher rates of lifetime trichotillomania while overweight and obese females reported higher rates of panic disorder. Higher educational institutions should be aware of the significant burden associated with overweight and obesity in students, and of the differing demographic and clinical associations between overweight or obesity in men and women.
\end{abstract}

Keywords. academic; college; education; health; impulse; obesity; weight 


\section{Introduction}

Obesity represents a leading public health concern, with the World Health Organization estimating that more than 1.4 billion individuals are obese worldwide (WHO, 2013). Although the rates of obesity have more than doubled in the general population since the 1980s, the greatest increase in rates of overweight individuals has continued to be young adults aged 18-29 year (Racette et al., 2005; Flegal et al., 2012). In fact, the American College Health Association (2011) reports that $34.1 \%$ of college students are currently overweight or obese.

Weight gain in college students is a particular concern given the large number of health problems associated with obesity, and young adults who are overweight will be exposed to greater cumulative risk over time (Finkelstein et al., 2008). The negative long-term consequences of being overweight include high blood pressure, heart disease, diabetes, arthritis-related disabilities, some cancers, and sleep apnea (Gortmaker et al., 1993; Poirier et al., 2006). The weight of college students, in particular women, is particularly important as the average age of first-time pregnancy is 25.8 years old in the US (Martin et al., 2013). Research has shown that women have a particular risk as overweight or obesity also increases the risk of pre-term delivery in females who are overweight or obese prior to pregnancy (Cnattingius et al., 2013) and is associated with reduced cognitive development in the early stages of their children post-partum (Casas et al., 2013).

College students who are overweight or obese report a range of emotional and social problems, including depression, stigmatization, and lower academic achievement (Adams and Colner, 2008; Desai et al., 2008). Both normal weight and obese women tend to report more mental symptoms than their male counterparts (Olsen et al., 2006; Luppino et al., 2008), 
however, it is currently unclear whether sex is a moderator of the relationship between mental distress and overweight status in college students. Less is known about the wider range of mental health effects - including psychiatric disorders such as those associated with impulsivity - in college students. The literature suggests that overweight and obesity are associated with difficulties inhibiting behaviors and higher sensitivity to reward (Mobbs et al., 2010; GarcíaGarcía et al., 2014), both features of impulsivity and impulsive behaviors. Very little is currently known, however, about whether overweight or obese individuals report higher rates of impulsive disorders, including gambling disorder, trichotillomania, and skin-picking disorder (amongst others) than their normal weight counterparts.

Therefore, this study sought to examine both the prevalence of a wide range of mental health disorders and associated health issues in male and female college students, who were categorized as being either normal weight, overweight or obese. We hypothesized that overweight and obese young adults, and in particular female students, would exhibit higher rates of most mental health disorders and have poorer self-esteem and greater impairments in academic performance. In addition, research indicates that the neurobiological underpinnings of obesity can be considered from the perspective of impulsivity (i.e. a tendency towards repetitive or habitual behaviors that are premature, risky, or poorly thought out) (e.g. Ziauddeen and Fletcher, 2013). Since being overweight in many individuals may be conceptualized as a problem with impulse control (Holdkamp et al., 2004; Braet et al., 2007) and reward processing deficiencies (García-García et al., 2014), we further hypothesized that being overweight would be associated with a variety of other impulsive behaviors. 


\section{Methods}

\subsection{Subjects}

A university psychiatry department and student health center collaborated to develop the College Student Computer User Survey (CSCUS) to assess mental and physical health in a large sample of college students. In addition to basic questions about age, sex, ethnicity, weight, and height, the CSCUS used questions from a number of different clinically validated screening tools to examine mental health, stress, quality of life, general physical health, and specific demographic information. All study procedures were carried out in accordance with the latest version of the Declaration of Helsinki and were approved by the Institutional Review Board.

A total of 6,000 full-time college and graduate students from a large Midwestern United States University were randomly invited via email to take part in the CSCUS. Invited participants were required to view the IRB-approved informed consent page at the beginning of the online survey. All individuals who completed the study either partially or fully were considered respondents. As compensation for the study, respondents were entered into a drawing to receive a gift certificate (\$250, \$500, and \$1000 USD), as well as three portable music devices. From the initial group of 6000 students contacted, 2,108 (35.1\%) completed the survey.

\subsection{Assessments}

The survey consisted of 129 questions, was entirely self-report, and took subjects approximately 30-45 minutes to complete. Survey questions consisted of demographic information, height and weight, health history, self-reported scholastic achievement (i.e., grade point average [GPA]), and psychosocial functioning. Subjects were also asked two questions about their perceived 
attractiveness (e.g., On a scale from 1-10 [1 being extremely unattractive and 10 being extremely attractive] how attractive are you and how attractive do you think others find you?). Subjects were also asked about their participation in extracurricular activities (including employment), mood, stress, psychiatric comorbidities, and items related to weight or weight loss, including weight loss attempts (and methods for weight loss). Amount of exercise was also reported and compared to the Center for Disease Control and Prevention's recommended amount of exercise per week, which entails 150 minutes of moderate-intensity aerobic activity a week, 75 minutes of vigorous-intensity aerobic activity a week, or an equivalent mix (Centers for Disease Control and Prevention [CDC], 2008).

Subjects completed the following measures:

Internet Addiction Test (IAT)(Young, 1998). The IAT is comprised of 20 questions examining levels of Internet use. Scores on the IAT range from 0-100 with 20-49 points reflecting mild Internet use, 50-79 moderate Internet use and 80-100 points for severe Internet use.

Patient Health Questionnaire (PHQ-9) (Kroenke and Spitzer, 2002; Kroenke et al., 2001). The PHQ-9 is a nine-item, client-administered scale based upon the diagnostic criteria for Major Depressive Disorder in the DSM-IV. It screens for current symptoms and functional impairment and provides a measure of depression severity.

Perceived Stress Scale (PSS) (Cohen et al., 1983). The PSS is a 10 item self-report measure assessing the degree to which individuals find their lives to be unpredictable, uncontrollable, and stressful. Each question is answered on a five-point Likert scale (ranging 
from "never" to "very often") based on experiences of the previous month. Scores range from 0 to 40 with higher scores indicating greater life stress.

Minnesota Impulsive Disorders Interview (MIDI) (Christenson et al., 1994; Grant, 2008).

The MIDI is a self-report scale for identifying intermittent explosive disorder, kleptomania, gambling disorder, compulsive sexual behavior, compulsive buying, excoriation (skin picking)

disorder, and trichotillomania. The MIDI has been used in previous studies assessing impulse control disorders in college students with good reliability (Odlaug and Grant, 2010). The questions mirror those in DSM-IV-TR (American Psychiatric Association, 2004) except for compulsive sexual behavior, compulsive buying, and excoriation (skin picking) disorder which use criteria proposed by Black et al. (1997), McElroy et al. (1994), and Arnold et al. (2001), respectively.

Participants were asked a series of questions about being diagnosed with various psychiatric disorders within their lifetime. Based on responses to these questions, a dichotomous variable was created with where ' 0 ' = report never being diagnosed with any of eleven possible psychiatric disorder and ' 1 ' = report being diagnosed with at least one of the eleven possible psychiatric disorders.

\subsection{Data Analysis}

As this study sought to examine a more traditional cohort of college students, the age range of our sample was limited to participants aged 18-40 with complete data. We applied a conservative upper limit of age at 40 years old in our analysis of the data in order to address outliers in our sample. This removal of subjects over the age of 40 applied to approximately $2 \%$ of all survey 
completers and was done to limit the negative effects on our statistical analysis (Osbourne and Overbay, 2004). These participants were then categorized a priori based on body mass index ranges as established by the CDC as being normal weight (BMI 18.5-24.9), overweight (BMI $\geq$ 25-29.9) or obese (BMI $\geq 30)(C D C, 2011)$. Analyses included: (1) prevalence of overweight and obese students and (2) cross-tabulation and t-test comparisons of those classified as being overweight versus the remaining respondents in terms of demographics, health behaviors, functioning and psychiatric diagnosis; (3) one-way ANOVA separated by normal weight, overweight, and obese, all stratified by sex; (4) logistic regression was conducted looking at an outcome of being diagnosed with at least one of the 11 listed psychiatric disorders run separately by sex and adjusting for age. Post hoc tests were conducted on significant variables, to correct for multiple comparisons, a Bonferroni correction was used which set significance at $\mathrm{p} \leq .008$. All analyses were conducted using SPSS version 22.

\section{Results}

A total of 2,108 (35.1\%; mean age 22.6士5.1 [range 18-58]; 78.8\% Caucasian; 41.8\% male) students completed the survey. Respondent demographics were not significantly different from the overall demographic profile of the University (41.4\% male; 79.5\% Caucasian). Of the 2,108 participants that completed the survey, 4 students were eliminated for inappropriate or careless responses (e.g., students who checked every possible box in the survey, with many of the responses of course contradicting each other) an additional 226 were removed because of missing data on sex, age, weight and height, 33 students were over the age of 40 . A total of 80 students whose BMI fell within the underweight category ( $n=80 ; 4.3 \%)$ were excluded as they 
the research questions posed here corresponded solely on overweight and obese subjects compared to normal weight individuals. After these exclusions, the final sample size was 1,765.

Of the 1,765 students, 492 (27.9\%) had an overweight or obese BMI ( $\mathrm{n}=356$ [20.2\%] overweight and $n=136$ [7.7\%] obese). Compared to students whose BMI placed them within the normal category overweight students were less likely to be female (60.7\% vs. $46.9 \%$ female students) (Table 1). The overweight and obese students were more likely to be older age (Table 1). There were no other significant demographic differences between the groups. Data surrounding behavioral activities engaged in, in order to lose weight, are given in Table 2. It can be seen that overweight students were significantly more likely to try to lose weight than their normal weight peers and they were more likely to use dieting and diet pills to lose weight.

Academic, physical and mental health comparison results are presented in Table 3. Obese male students reported significantly more depressive symptoms (PHQ-9 scores) compared to male students classified as normal weight $(\mathrm{F}[2,64]=5.19 ; \mathrm{p}=0.006)$, and considered themselves significantly less attractive than their normal weight and overweight peers (Table 3) while overweight females had higher rates of perceived stress $(\mathrm{F}[2,944]=4.09 ; \mathrm{p}=0.017)$.

In terms of categorical psychiatric diagnosis, obese male students were significantly more likely to report histories of major depressive disorder compared to overweight and normal weight male students ( $28.6 \%, 9.5 \%$ and $10.6 \%$, respectively-; $\chi^{2}=16.91 ; \mathrm{df}=2 ; \mathrm{p}<0.001$ ). Obese female students reported significantly higher rates of being diagnosed with major depressive and panic disorders (Table 4). In addition, generalized anxiety, panic, and social anxiety disorders were more common, and showed a statistical trend toward significance in obese males compared to overweight and normal weight males (Table 4). Finally, on the MIDI, obese male students 
screened positive for higher rates of trichotillomania (5.4\%) compared to their overweight (0.6\%) and normal $(0.4 \%)$ weight peers $(\mathrm{p}=0.009)$.

Results of a logistic regression analyses of being diagnosed with at least one of the 11 listed psychiatric disorders stratified by sex and adjusting for age, are shown in Table 5 . The results showed the odds of being diagnosed with a psychiatric disorder within lifetime in obese males was 156\% higher than normal weight male students (OR=2.56; 95\% CI: 1.411-4.633), statistically significant at $(\mathrm{p}=0.002)$.

\section{Discussion}

We found a rate of overweight (20.2\%) and obesity (7.7\%) in this college student population, a rate significantly lower than the $68.5 \%$ of adults in the US who are overweight or obese (Ogden et al., 2014). Since the survey was entirely self-report, including height and weight, based on the literature (e.g., Elgar et al., 2005; Ezzati et al., 2006; Krul et al., 2010) it is likely that weight was under-estimated by subjects while height may have been over-reported. Any under-reporting of weight and over-estimation of height would have a significant impact on the calculation of BMI in these students. From a positive standpoint, it is likely that the population of overweight and obese that we did assess here were indeed overweight or obese and probably more so based on under-reporting of weight and over-reporting of height noted in previous research (Elgar et al., 2005; Ezzati et al., 2006; Krul et al., 2010).

Noteworthy findings from this study included that both male and female students who were overweight or obese reported significantly lower overall academic achievement as measured by Grade Point Average (GPA), had more depressive symptoms, perceived themselves 
as being less attractive (both to themselves and others), and reported higher lifetime rates of major depression. Interestingly, obese males reported higher rates of trichotillomania (TTM), a disorder characterized as an impulsive disorder and largely thought to have a high female preponderance (Lochner et al., 2012), suggesting that screening for TTM should not be limited to the female population and may indicate a subtype in which TTM may be particularly common in males. Further, obesity and TTM have never been associated in the literature and our results perhaps warrant additional investigation as they may reflect some underlying commonality in compulsivity. While the rates of TTM did not differ in females in this sample as a function of weight status, overweight/obese females had higher rates of perceived stress and a lifetime history of panic disorder, all of which may influence overall academic achievement and quality of life. The significantly higher occurrence of panic disorder in obese females has been demonstrated in previous research (for a review see Lykouras and Michopoulos, 2011) and may indicate a possible biological connection between these conditions. Overall, these results further illustrate the deleterious effects of overweight and obesity in young adults noted in previous research (Adams and Colner, 2008; Desai et al., 2008).

Distorted body image and body dissatisfaction are prevalent among college students, particularly women. Research has shown that body and weight perceptions are more important for weight loss strategies than actual weight status (Harring et al., 2010). Previous research on college students noted that over $50 \%$ of college students report actively trying to lose weight despite the fact that only about $25 \%$ are overweight or obese (Wharton et al., 2008). This may explain why $75 \%$ of the normal weight participants reported to have tried to lose weight. We note that significantly more overweight and obese students engaged in activities to lose weight, 
however, the significantly higher percentage of overweight and obese students using diet or diet pills raises concerns. While over 100 over-the-counter weight loss supplements currently exist on the market, the efficacy and safety of these supplements is far from clear (Saper et al., 2004). Indeed, the Food and Drug Administration (FDA) has banned the sale of a number of weight loss related products. Health officials at schools should be aware of the use of these supplements and ask students about them as part of routine health assessments while encouraging more traditional forms of weight loss and control, including healthy diet and exercise. Such results emphasize the importance of considering the degree to which inaccurate body weight perception may drive healthy or unhealthy weight loss practices (Malinauskas et al., 2006). If not, promising and wellintentioned programs may end up promoting unhealthy behavior.

The study also found lower academic achievement in overweight and obese males and females which is consistent with the extant literature. What is unclear and disputed in the literature, however, is whether having a lower grade point average predisposes one to becoming overweight or obese or vice versa and whether lifestyle interventions may help with both school success and weight management (Martin et al., 2014). A large study in the UK, examining longitudinal associations between weight and academic performance, found that weight at a young age was predictive of subsequent academic achievement in adolescence for girls but not boys (Booth et al., 2014). Such continued research using longitudinal methods may help to shed light on the impact of young-age overweight and obesity on later life achievement, health, and well-being.

There are a number of caveats from the current study that must be noted. The study design was cross-sectional with inherent difficulties in establishing causal relationships and data 
were obtained by self-report (Internet-based questionnaires), rather than in person using clinical interviews. As such the findings may be affected by bias (e.g. under-reporting) and a lower degree of accuracy than might otherwise have been obtained. For example, and as noted earlier, previous research indicates that women underreport their current weight (Ezzati et al., 2006) which may have led to miscategorization of our sample into the three specified categories of weight for this study. Future studies utilizing direct interviews or using national health data may eliminate over- or under-reporting of weight and height and lead to a better understanding of the effects of weight on health and academic performance. Second, and although the promotion of healthy lifestyle and weight management are important, we did not ask follow-up questions about dieting practices, an item that was noted to be significantly higher in the overweight and obese population in this study. Recent research indicates that unhealthy weight loss behaviors, including fasting and purging, occurs in a significant proportion of overweight and obese college students (Davila et al., 2014) and could have been examined more thoroughly in this study. Third, and due to time constraints and in order to lessen the burden of questions for participants, we did not used validated measures to assess many conditions (for example, psychiatric history). As such, the reliability of the reported results cannot be fully assured. Fourth, there is a possible lack of generalizability of our results due to the Midwestern United States sample with a predominantly White student population. Further, we did not include a measure of socioeconomic status nor did we clarify the duration of weight status (e.g., childhood onset versus adolescent onset), both of which are factors associated with weight status (Stunkard and Sørensen, 1993; Gortmaker et al., 1993). Finally, the cross-sectional nature of this study does not allow for conclusions of causal or predictive factors related to overweight or obesity in college 
students. While longitudinal designs have been utilized in previous studies of children (e.g. Booth et al., 2014), tracking individuals from an even younger age should be considered to examine the causal effects of weight on health and achievement.

\subsection{Conclusions}

By the year 2030, it is projected that over half (51\%) of the United States population will be obese (Finkelstein et al., 2012). Given the comorbid physical and mental health conditions often associated with overweight and obesity and the significant individual and societal health and economic burden, initiatives have been implemented to stem the further growth of these numbers in childhood (WHO, 2012), including recommendations from the CDC. While these initiatives and recommendations have been useful, higher educational institutions should be aware of the continued and significant burden associated with overweight and obesity in their students, and of the differing demographic and clinical associations between men and women with obesity. The results from the current study underscore the often significant and negative effects of weight on student psychiatric health, academic achievement, and self-perception. The recognition that weight plays a role in such facets of student health should prompt faculty and administrative entities within the collegiate system to form strategies for targeted invention in order to improve the overall quality of life for these individuals. With a ever-expanding cohort of overweight and obesity worldwide, such public health initiatives should comprise a priority within the academic sector of society.

Funding. Internal funds. 
Acknowledgements. None.

Contributors. Mr. Odlaug and Dr. Grant co-wrote the initial draft of the manuscript and developed the method of analysis. Dr. Lust performed the statistical analysis and added the data analysis section. Ms. Wimmelmann, Dr. Chamberlain, Dr. Mortensen, Ms. Derbyshire, and Dr. Christenson added relevant literature and content to the manuscript and suggested additional analyses where prudent. All authors read and approve of the final version of the manuscript.

Conflicts of Interest. Mr. Odlaug has received a research grant from the Trichotillomania Learning Center, consults for $\mathrm{H}$. Lundbeck A/S, and receives royalties from Oxford University Press. Dr. Grant has research grants from National Center for Responsible Gaming, Forest Pharmaceuticals and Roche Pharmaceuticals. He receives yearly compensation from Springer Publishing for acting as Editor-in-Chief of the Journal of Gambling Studies and has received royalties from Oxford University Press, American Psychiatric Publishing, Inc., Norton Press, and McGraw Hill. Dr. Chamberlain consults for Cambridge Cognition. Dr. Lust, Ms. Wimmelmann, Dr. Mortensen, Ms. Derbyshire, and Dr. Christenson report no financial relationships with commercial interests. 


\section{References}

Adams, T.B., Colner, W., 2008. The association of multiple risk factors with fruit and vegetable intake among a nationwide sample of college students. Journal of American College Health 56, 455-461.

American College Health Association., 2011. National college health assessment II: Fall 2011 reference group executive summary. American College Health Association, Hanover.

American Psychiatric Association., 2004. Diagnostic and statistical manual of mental disorders, $4^{\text {th }}$ edition, text-revision. American Psychiatric Association, Washington, D.C.

Arnold, L.M., Auchenbach, M.B., McElroy, S.L., 2001. Psychogenic excoriation: clinical features, proposed diagnostic criteria, epidemiology and approaches to treatment. CNS Drugs 15, 351-359.

Black, D.W., Kehrberg, L.L., Flumerfelt, D.L., Schlosser, S.S., 1997. Characteristics of 36 subjects reporting compulsive sexual behavior. American Journal of Psychiatry 154, 243-249.

Booth, J.N., Tomporowski, P.D., Boyle, J.M., Ness, A.R., Joinson, C., Leary, S.D., Reilly, J.J., 2014. Obesity impairs academic attainment in adolescence: findings from ALSPAC, a UK cohort. International Journal of Obesity (London) doi: 10.1038/ijo.2014.40.

Braet, C., Claus, L., Verbeken, S., Van Vlierberghe, L., 2007. Impulsivity in overweight children. European Child \& Adolescent Psychiatry 16, 473-483.

Centers for Disease Control and Prevention (CDC), 2011. Body mass index for adults. Available at http://www.cdc.gov/healthyweight/assessing/bmi/adult_bmi/. Last updated September 13, 2011. Accessed on April 9, 2014.

Casas, M., Chatzi, L., Carsin, A.E., Amiano, P., Guxens, M., Kogevinas, M., Koutra, K., Lertxundi, N., Murcia, M., Rebagliato, M., Riaño, I., Rodríguez-Bernal, C.L., Roumeliotaki, T., Sunyer, J., Mendez, M., Vrijheid, M., 2013. Maternal pre-pregnancy overweight and obesity, and child neuropsychological development: two Southern European birth cohort studies. International Journal of Epidemiology 42, 506-517.

Christenson, G.A., Faber, R.J., de Zwaan, M., Raymond, N.C., Specker, S.M., Ekern, M.D., Mackenzie, T.B., Crosby, R.D., Crow, S.J., Eckert, E.D., 1994. Compulsive buying: descriptive characteristics and psychiatric comorbidity. Journal of Clinical Psychiatry 55, 5-11.

Cnattingius, S., Villamor, E., Johansson, S., Edstedt Bonamy, A.K., Persson, M., Wikström, A.K., Granath, F, 2013. Maternal obesity and risk of preterm delivery. JAMA 309, 2362-2370. 
Cohen, S., Kamarck, T., Mermelstein, R., 1983. A global measure of perceived stress. Journal of Health and Social Behavior 24, 386-396.

Davila, E.P., Kolodziejczyk, J.K., Norman, G.J., Calfas, K., Huang, J.S., Rock, C.L., Griswold, W., Fowler, J.H., Marshall, S.J., Gupta, A., Patrick, K., 2014. Relationships between depression, gender, and unhealthy weight loss practices among overweight or obese college students. Eating Behaviors 15, 271-274.

Desai, M.N., Miller, W.C., Staples, B., Bravender, T., 2008. Risk factors associated with overweight and obesity in college students. Journal of American College Health 57, 109-114.

Elgar, F.J., Roberts, C., Tudor-Smith, C., Moore, L., 2005. Validity of self-reported height and weight and predictors of bias in adolescents. Journal of Adolescent Health 37, 371-375.

Ezzati, M., Martin, H., Skjold, S., Vander Hoorn, S., Murray, C.J., 2006. Trends in national and state-level obesity in the USA after correction for self-report bias: analysis of health surveys. Journal of the Royal Society of Medicine 99, 250-257.

Finkelstein, E.A., Trogdon, J.G., Brown, D.S., Allaire, B.T., Dellea, P.S., Kamal-Bahl, S.J., 2008. The lifetime medical cost burden of overweight and obesity: implications for obesity prevention. Obesity (Silver Spring) 16, 1843-1848.

Finkelstein, E.A., Khavjou, O.A., Thompson, H., Trogdon, J.G., Pan, L., Sherry, B., Dietz, W., 2012. Obesity and severe obesity forecasts through 2030. American Journal of Preventative Medicine 42, 563-570.

Flegal, K.M., Carroll, M.D., Kit, B.K., Ogden, C.L., 2012. Prevalence of obesity and trends in the distribution of body mass index among US adults, 1999-2010. Journal of the American Medical Association 307, 491-497.

García-García, I., Horstmann, A., Jurado, M.A., Garolera, M., Chaudhry, S.J., Margulies, D.S., Villringer, A., Neumann, J., 2014. Reward processing in obesity, substance addiction and nonsubstance addiction. Obesity Reviews 15, 853-869.

Gortmaker, S.L., Must, A., Perrin, J.M., Sobol, A.M., Dietz, W.H., 1993. Social and economic consequences of overweight in adolescence and young adulthood. New England Journal of Medicine 329, 1008-1012.

Grant, J.E., 2008. Impulse Control Disorders: A Clinician's Guide to Understanding and Treating Behavioral Addictions. Norton W.W. and Company, New York.

Harring HA, Montgomery K, Hardin J., 2010. Perceptions of body weight, weight management strategies, and depressive symptoms among US college students. Journal of American College Health 59, 43-50. 
Holtkamp, K., Konrad, K., Müller, B., Heussen, N., Herpertz, S., Herpertz-Dahlmann, B., Hebebrand, J., 2004. Overweight and obesity in children with Attention-Deficit/Hyperactivity Disorder. International Journal of Obesity and Related Metabolic Disorders 28, 685-689.

Kroenke, K., Spitzer, R.L., Williams, J.B., 2001. The PHQ-9: validity of a brief depression severity measure. Journal of General Internal Medicine 16, 606-613.

Kroenke, K., Spitzer, R.L., 2002. The PHQ-9: a new depression and diagnostic severity measure. Psychiatric Annals 32, 509-521.

Krul, A.J., Daanen, H.A., Choi, H., 2011. Self-reported and measured weight, height and body mass index (BMI) in Italy, the Netherlands and North America. European Journal of Public Health 21, 414-419.

Lochner, C., Grant, J.E., Odlaug, B.L., Woods, D.W., Keuthen, N.J., Stein, D.J., 2012. DSM-5 field survey: hair-pulling disorder (trichotillomania). Depression \& Anxiety 29, 1025-1031.

Lykouras, L., Michopoulos, J., 2011. Anxiety disorders and obesity. Psychiatriki 22, 307-313.

Malinauskas, B.M., Raedeke, T.D., Aeby, V.G., Smith, J.L., Dallas, M.B., 2006. Dieting practices, weight perceptions, and body composition: a comparison of normal weight, overweight, and obese college females. Nutrition Journal 5, 11.

Martin, A., Saunders, D.H., Shenkin, S.D., Sproule, J., 2014. Lifestyle intervention for improving school achievement in overweight or obese children and adolescents. Cochrane Database of Systematic Reviews 3, CD009728.

Martin, J.A., Hamilton, B.E., Osterman, M.J.K, Curtin, S.C., Mathews, T.J., 2013. Births: Final data for 2012. National vital statistics reports; vol. 62, no. 9. Hyattsville, MD: National Center for Health Statistics.

McElroy, S.L., Keck, P.E. Jr., Pope, H.G. Jr., Smith, J.M., Strakowski, S.M., 1994. Compulsive buying: a report of 20 cases. Journal of Clinical Psychiatry 55, 242-248.

Mobbs, O., Crépin, C., Thiéry, C., Golay, A., Van der Linden, M., 2010. Obesity and the four facets of impulsivity. Patient Education and Counseling 79, 372-377.

Ogden, C.L., Carroll, M.D., Kit, B.K., Flegal, K.M., 2014. Prevalence of childhood and adult obesity in the United States, 2011-2012. JAMA 311, 806-814.

Odlaug, B.L., Grant, J.E., 2010. Impulse-control disorders in a college sample: results from the self-administered Minnesota Impulse Disorders Interview (MIDI). Primary Care Companion to the Journal of Clinical Psychiatry 12, e1-e5. 
Osborne, J.W., Overbay, A., (2004). The power of outliers (and why researchers should always check for them). Practical Assessment, Research \& Evaluation, 9(6). Available from http://PAREonline.net/getvn.asp?v=9\&n=6

Poirier, P., Giles, T.D., Bray, G.A., Hong, Y., Stern, J.S., Pi-Sunyer, F.X., Eckel, R.H.; American Heart Association; Obesity Committee of the Council on Nutrition, Physical Activity, and Metabolism., 2006. Obesity and cardiovascular disease: pathophysiology, evaluation, and effect of weight loss: an update of the 1997 American Heart Association Scientific Statement on Obesity and Heart Disease from the Obesity Committee of the Council on Nutrition, Physical Activity, and Metabolism. Circulation 113, 898-918.

Racette, S.B., Deusinger, S.S., Strube, M.J., Highstein, G.R., Deusinger, R.H., 2005. Weight changes, exercise, and dietary patterns during freshman and sophomore years of college. Journal of American College Health 53, 245-251.

Saper, R.B., Eisenberg, D.M., Phillips, R.S., 2004. Common dietary supplements for weight loss. American Family Physician 70, 1731-1738.

Stunkard, A.J., Sørensen, T.I., 1993. Obesity and socioeconomic status - a complex relation. New England Journal of Medicine 329, 1036-1037.

Torrijos-Niño, C., Martínez-Vizcaíno, V., Pardo-Guijarro, M.J., García-Prieto, J.C., AriasPalencia, N.M., Sánchez-López, M., 2014. Physical Fitness, Obesity, and Academic Achievement in Schoolchildren. Journal of Pediatrics doi: 10.1016/j.jpeds.2014.02.041.

Wharton, C.M., Adams, T., Hampl, J.S., 2008. Weight loss practices and body weight perceptions among US college students. Journal of American College Health 56, 579-584.

World Health Organization., 2012. Population-based approaches to childhood obesity prevention. World Health Organization, Geneva.

World Health Organization., 2013. Obesity and overweight: fact sheet. Available at http://www.who.int/mediacentre/factsheets/fs311/en/. Last updated March 2013. Accessed on April 22, 2014.

Young, K.S., 1998. Internet addiction: the emergence of a new clinical disorder. CyberPsychology \& Behavior 3, 237-244.

Ziauddeen, H., Fletcher, P.C., 2013. Is food addiction a valid and useful concept? Obesity Reviews 14, 19-28. 
Table 1. Demographic Characteristics of College Students Grouped by Body Mass Index

\begin{tabular}{|c|c|c|c|c|c|}
\hline Variable & $\begin{array}{c}\text { Normal } \\
\text { Weight } \\
\mathrm{N}=1273\end{array}$ & $\begin{array}{l}\text { Overweight } \\
\qquad N=356\end{array}$ & $\begin{array}{c}\text { Obese } \\
N=136\end{array}$ & $\begin{array}{c}\text { Test } \\
\text { statistic }\end{array}$ & p-value \\
\hline Age, Mean (SD) & $21.82(3.4)$ & $23.02(4.4)$ & $23.74(4.8)$ & $\begin{array}{l}\mathrm{F}(2,1762) \\
\quad=26.79\end{array}$ & $<0.001$ \\
\hline $\begin{array}{l}\text { Gender } \\
\text { Female }\end{array}$ & 60.7 (773) & 46.9 (167) & $58.8(80)$ & $\begin{array}{c}\chi^{2}=21.82 \\
\mathrm{df}=2\end{array}$ & $<0.001$ \\
\hline $\begin{array}{l}\text { Body Mass Index, } \\
\text { Mean (SD) }\end{array}$ & $21.94(1.7)$ & $26.63(1.3)$ & $35.12(6.4)$ & $\begin{array}{l}F(2,1762) \\
=2291.31\end{array}$ & $<0.001$ \\
\hline \multicolumn{6}{|l|}{ Race/Ethnicity } \\
\hline White/Caucasian & 81.5 (1038) & $79.2(282)$ & $73.5(100)$ & & \\
\hline African & $0.9(11)$ & $2.2(8)$ & $2.9(4)$ & & \\
\hline African-American & $0.9(12)$ & $0.8(3)$ & $2.9(4)$ & & \\
\hline Asian/Pacific Islander & $10.3(131)$ & $9.6(34)$ & $10.3(14)$ & & \\
\hline Latino & $1.6(20)$ & $3.1(11)$ & $2.2(3)$ & & \\
\hline Middle eastern & $0.7(9)$ & $0.8(3)$ & $0.0(0)$ & & \\
\hline Other & $3.8(49)$ & $3.4(12)$ & $7.4(10)$ & & \\
\hline *Non-White Only & $18.3(232)$ & $20.1(71)$ & $25.9(35)$ & $\begin{array}{c}\chi^{2}=0.433 \\
\mathrm{df}=2\end{array}$ & 0.089 \\
\hline $\begin{array}{l}\text { Relationship Status } \\
\text { Single }\end{array}$ & $57.9(736)$ & 57.7 (205) & $60.7(82)$ & $\begin{array}{c}\chi^{2}=4.99 \\
\mathrm{df}=2\end{array}$ & 0.805 \\
\hline $\begin{array}{l}\text { Student Status } \\
\text { Undergraduate }\end{array}$ & 79.3 (1007) & 74.9 (263) & $74.1(100)$ & $\begin{array}{c}\chi^{2}=4.378 \\
\mathrm{df}=2\end{array}$ & 0.112 \\
\hline $\begin{array}{l}\text { International } \\
\text { Students }\end{array}$ & $5.0(63)$ & $6.5(23)$ & $5.2(7)$ & $\begin{array}{c}\chi^{2}=1.28 \\
\mathrm{df}=2\end{array}$ & 0.527 \\
\hline
\end{tabular}

All values are \% (n) unless otherwise noted

*Respondent did not select White/Caucasian but did select at least one of the other race/ethnicity groups 
Table 2. Engagement in Activities to Lose Weight based on Body Mass Index

\begin{tabular}{|c|c|c|c|c|c|}
\hline & $\begin{array}{c}\text { Normal } \\
\text { Weight } \\
\mathrm{N}=1273\end{array}$ & $\begin{array}{l}\text { Overweight } \\
\qquad \mathrm{N}=356\end{array}$ & $\begin{array}{c}\text { Obese } \\
N=136\end{array}$ & $\begin{array}{c}\text { Test } \\
\text { statistic* }\end{array}$ & p-value \\
\hline $\begin{array}{l}\text { Engaged in an activity } \\
\text { to lose weight }\end{array}$ & $73.4(935)_{a}$ & $87.4(311)_{b}$ & $90.4(123)_{b}$ & $\begin{array}{c}\chi^{2}=44.98 \\
\mathrm{df}=2\end{array}$ & $<0.001^{* *}$ \\
\hline \multicolumn{6}{|c|}{ Among those who engaged in an activity to lose weight: activity they engaged in } \\
\hline Skip meals & $26.5(248)$ & $26.0(81)$ & $26.8(33)$ & $\begin{array}{c}\chi^{2}=0.038 \\
\mathrm{df}=2\end{array}$ & 0.980 \\
\hline Smoke tobacco & $4.2(39)$ & $4.5(14)$ & $3.3(4)$ & $\begin{array}{c}\chi^{2}=0.345 \\
\mathrm{df}=2\end{array}$ & 0.865 \\
\hline Exercise & $80.3(751)$ & 85.9 (267) & 80.5 (99) & $\begin{array}{c}\chi^{2}=4.864 \\
\mathrm{df}=2\end{array}$ & 0.089 \\
\hline Use diet pills & $3.2(30)_{\mathrm{a}}$ & $5.5(17)_{\mathrm{a}, \mathrm{c}}$ & $7.3(9)_{b, c}$ & $\begin{array}{c}\chi^{2}=6.618 \\
\mathrm{df}=2\end{array}$ & $0.036^{* *}$ \\
\hline Use illegal drugs & $0.9(8)$ & $0.3(1)$ & $0.0(0)$ & $*$ & 0.549 \\
\hline Eat healthier & $84.2(787)$ & $87.5(272)$ & $84.6(104)$ & $\begin{array}{c}\chi^{2}=1.991 \\
\mathrm{df}=2\end{array}$ & 0.379 \\
\hline Vomit after eating & $3.1(29)$ & $3.2(10)$ & $1.6(2)$ & $*$ & 0.789 \\
\hline Use laxatives & $1.3912)$ & $0.3(1)$ & $0.0(0)$ & $*$ & 0.231 \\
\hline Diet & $10.8(101)_{\mathrm{a}}$ & $17.4(54)_{b}$ & $18.7(23)_{b}$ & $\begin{array}{c}\chi^{2}=12.759 \\
\mathrm{df}=2\end{array}$ & $0.002^{* *}$ \\
\hline Have had surgery & $0.0(0)$ & $0.3(1)$ & $0.0(0)$ & $*$ & 0.317 \\
\hline
\end{tabular}

All values are \% (n) unless otherwise noted; $\mathrm{df}=2$; *Fisher's Exact Test ${ }^{* *}$ Significant using Holm Sequentially Rejective adjustment.

For each pair of columns, the column proportions are compared using a $z$ test. If a pair of values is significantly different at the 0.05 level, the values have different subscript letters assigned to them. 
Table 3. Academic and Health Indices of Weight Stratified by Sex

\begin{tabular}{|c|c|c|c|c|c|c|c|c|c|c|}
\hline & \multicolumn{3}{|c|}{$\begin{array}{l}\text { Males } \\
\mathrm{N}=745\end{array}$} & \multirow{2}{*}{$\begin{array}{c}\text { Test } \\
\text { statistic }\end{array}$} & \multirow[b]{2}{*}{ p-value } & \multicolumn{3}{|c|}{$\begin{array}{l}\text { Females } \\
\mathrm{N}=1020\end{array}$} & \multirow{2}{*}{$\begin{array}{c}\text { Test } \\
\text { statistic }\end{array}$} & \multirow[b]{2}{*}{ p-value } \\
\hline & $\begin{array}{c}\text { Normal } \\
\mathrm{N}=500\end{array}$ & $\begin{array}{c}\text { Overweight } \\
\mathbf{N}=\mathbf{1 8 9}\end{array}$ & $\begin{array}{l}\text { Obese } \\
\mathrm{N}=56\end{array}$ & & & $\begin{array}{c}\text { Normal } \\
\mathrm{N}=773\end{array}$ & $\begin{array}{c}\text { Overweight } \\
\mathrm{N}=167\end{array}$ & $\begin{array}{l}\text { Obese } \\
\mathrm{N}=\mathbf{8 0}\end{array}$ & & \\
\hline $\begin{array}{l}\text { College Grade Point } \\
\text { Average }\end{array}$ & $3.34(.50)$ & $3.32(.49)$ & $\begin{array}{l}3.13 \\
(.57)\end{array}$ & $\begin{array}{l}\mathrm{F}(2,734) \\
\quad=4.67\end{array}$ & $0.010^{* *}$ & $\begin{array}{l}3.42 \\
(.42)\end{array}$ & $3.27(.52)$ & $\begin{array}{l}3.23 \\
(.54)\end{array}$ & $\begin{array}{l}F(2,1001) \\
=12.31\end{array}$ & $\begin{array}{c}<0.001^{* *} \\
\text { a, b }\end{array}$ \\
\hline $\begin{array}{l}\text { Meet adult CDC } \\
\text { physical activity } \\
\text { recommendations \% } \\
\text { (n) }\end{array}$ & $\begin{array}{l}61.3 \\
(304)\end{array}$ & $63.5(120)$ & $\begin{array}{l}49.1 \\
(27)\end{array}$ & $\begin{array}{c}\chi^{2}=3.79 \\
\mathrm{df}=2\end{array}$ & 0.148 & $\begin{array}{l}54.7 \\
(420)\end{array}$ & $46.3(76)$ & $\begin{array}{l}52.5 \\
(42)\end{array}$ & $\begin{array}{c}\chi^{2}=3.80 \\
\mathrm{df}=2\end{array}$ & 0.150 \\
\hline PHQ-9 (Score 0-27) & $4.12(4.1)$ & $4.43(4.4)$ & $\begin{array}{l}6.04 \\
(4.6)\end{array}$ & $\begin{array}{l}\mathrm{F}(2,684) \\
\quad=5.19\end{array}$ & $\begin{array}{c}0.006^{* *} \\
b\end{array}$ & $\begin{array}{l}5.07 \\
(4.5)\end{array}$ & $6.15(5.1)$ & $\begin{array}{l}5.59 \\
(4.1)\end{array}$ & $\begin{array}{l}\mathrm{F}(2,938) \\
\quad=3.63\end{array}$ & $0.027^{* *}$ \\
\hline $\begin{array}{l}\text { Perceived Stress } \\
\text { Score (Score 0-40) }\end{array}$ & $\begin{array}{l}14.75 \\
(6.5)\end{array}$ & $14.58(6.0)$ & $\begin{array}{l}16.79 \\
(6.7)\end{array}$ & $\begin{array}{l}\mathrm{F}(2,692) \\
=2.62\end{array}$ & 0.073 & $\begin{array}{l}16.71 \\
(6.4)\end{array}$ & $18.41(8.0)$ & $\begin{array}{l}17.16 \\
(6.1)\end{array}$ & $\begin{array}{l}\mathrm{F}(2,944) \\
\quad=4.09\end{array}$ & $0.017^{* *}$ \\
\hline $\begin{array}{l}\text { Internet Addiction } \\
\text { Score (Score 0-100) }\end{array}$ & $\begin{array}{l}29.85 \\
(10.8)\end{array}$ & $29.58(11.2)$ & $\begin{array}{l}33.36 \\
(13.7)\end{array}$ & $\begin{array}{l}\mathrm{F}(2,695) \\
=2.58\end{array}$ & 0.077 & $\begin{array}{l}29.48 \\
(11.1)\end{array}$ & $31.24(10.3)$ & $\begin{array}{l}30.23 \\
(11.5)\end{array}$ & $\begin{array}{l}\mathrm{F}(2,939) \\
=1.67\end{array}$ & 0.189 \\
\hline $\begin{array}{l}\text { Perceived } \\
\text { Attractiveness } \\
\text { (Perception of Self) (0- } \\
10)^{*}\end{array}$ & $7.10(1.4)$ & $7.03(1.2)$ & $\begin{array}{l}5.77 \\
(2.0)\end{array}$ & $\begin{array}{l}\mathrm{F}(2,728) \\
=23.19\end{array}$ & $\begin{array}{c}<0.001^{* *} \\
b, c\end{array}$ & $\begin{array}{l}6.97 \\
(1.3)\end{array}$ & $6.15(1.5)$ & $\begin{array}{l}5.49 \\
(1.7)\end{array}$ & $\begin{array}{l}F(2,1003) \\
\quad=59.69\end{array}$ & $\begin{array}{c}<0.001^{* *} \\
\text { a, b, c }\end{array}$ \\
\hline $\begin{array}{l}\text { Perceived } \\
\text { Attractiveness } \\
\text { (Perception by others) } \\
(0-10)^{*}\end{array}$ & $7.44(1.4)$ & $7.25(1.2)$ & $\begin{array}{l}6.39 \\
(1.9)\end{array}$ & $\begin{array}{l}\mathrm{F}(2,729) \\
=15.06\end{array}$ & $\begin{array}{l}<0.001^{* *} \\
\text { b, c }\end{array}$ & $\begin{array}{l}7.64 \\
(1.3)\end{array}$ & $7.13(1.4)$ & $\begin{array}{l}6.41 \\
(1.6)\end{array}$ & $\begin{array}{l}\mathrm{F}(2,1000) \\
=37.84\end{array}$ & $\begin{array}{c}<0.001^{* *} \\
\text { a, b, c }\end{array}$ \\
\hline
\end{tabular}


Table 4. Psychiatric Disorder Screening Sorted by Weight and Stratified by Sex

\begin{tabular}{|c|c|c|c|c|c|c|c|c|c|c|}
\hline & \multicolumn{3}{|c|}{$\begin{array}{l}\text { Males } \\
\mathrm{N}=745\end{array}$} & \multirow{2}{*}{$\begin{array}{c}\text { Test } \\
\text { statistic }\end{array}$} & \multirow[b]{2}{*}{ p-value } & \multicolumn{3}{|c|}{$\begin{array}{l}\text { Females } \\
\mathrm{N}=1020\end{array}$} & \multirow{2}{*}{$\begin{array}{c}\text { Test } \\
\text { statistic }\end{array}$} & \multirow[b]{2}{*}{ p-value } \\
\hline & $\begin{array}{c}\text { Normal } \\
N=500\end{array}$ & $\begin{array}{c}\text { Overweight } \\
\text { N=189 }\end{array}$ & $\begin{array}{l}\text { Obese } \\
N=56\end{array}$ & & & $\begin{array}{c}\text { Normal } \\
N=773\end{array}$ & $\begin{array}{c}\text { Overweight } \\
\mathbf{N}=\mathbf{1 6 7} \\
\end{array}$ & $\begin{array}{l}\text { Obese } \\
\mathbf{N}=\mathbf{8 0}\end{array}$ & & \\
\hline \multicolumn{11}{|c|}{ Lifetime self-report diagnoses } \\
\hline $\begin{array}{l}\text { Major Depressive } \\
\text { Disorder }\end{array}$ & $10.6(53)_{\mathrm{a}}$ & $9.5(18)_{a}$ & $28.6(16)_{b}$ & $\begin{array}{l}\chi^{2}=16.91 \\
\mathrm{df}=2\end{array}$ & $<0.001^{* *}$ & $\begin{array}{l}19.1 \\
(148)_{a}\end{array}$ & $27.5(46)_{b}$ & $31.3(25) \mathrm{b}$ & $\begin{array}{l}\chi^{2}=10.67 \\
\mathrm{df}=2\end{array}$ & $0.005^{* *}$ \\
\hline Bipolar Disorder & $0.8(4)$ & $0.5(1)$ & $0.0(0)$ & $*$ & 1.000 & $0.9(7)$ & $1.8(3)$ & $1.3(1)$ & $*$ & 0.456 \\
\hline $\begin{array}{l}\text { Generalized anxiety } \\
\text { disorder }\end{array}$ & $5.2(26)$ & $5.3(10)$ & $14.3(8)$ & $\begin{aligned} \chi^{2} & =7.65 \\
\mathrm{df} & =2\end{aligned}$ & 0.027 & $10.6(82)$ & $11.4(19)$ & $15.0(12)$ & $\begin{array}{l}\chi^{2}=1.438 \\
\mathrm{df}=2\end{array}$ & 0.487 \\
\hline Panic Disorder & $2.2(11)$ & $1.6(3)$ & $8.9(5)$ & $*$ & 0.019 & $6.2(48)_{a}$ & $7.2(12)_{a, b}$ & $15.0(12)_{b}$ & $\begin{aligned} \chi^{2} & =8.54 \\
\mathrm{df} & =2\end{aligned}$ & $0.014^{* *}$ \\
\hline $\begin{array}{l}\text { Social Anxiety } \\
\text { Disorder }\end{array}$ & $3.6(18)$ & $4.8(9)$ & $12.5(7)$ & $*$ & 0.018 & $4.1(32)$ & $3.0(5)$ & $2.5(2)$ & $*$ & 0.806 \\
\hline $\begin{array}{l}\text { Obsessive } \\
\text { Compulsive } \\
\text { Disorder }\end{array}$ & $1.6(8)$ & $1.1(2)$ & $5.4(3)$ & $*$ & 0.103 & $2.2(17)$ & $2.4(4)$ & $1.3(1)$ & $*$ & 0.931 \\
\hline $\begin{array}{l}\text { Post-Traumatic } \\
\text { Stress Disorder }\end{array}$ & $1.0(5)$ & $1.1(2)$ & $3.6(2)$ & $*$ & 0.245 & $2.2(17)$ & $2.4(4)$ & $3.8(3)$ & $*$ & 0.577 \\
\hline $\begin{array}{l}\text { Any Substance Use } \\
\text { Disorder }\end{array}$ & $2.0(10)$ & $1.6(3)$ & $0.0(0)$ & $*$ & 0.901 & $1.0(8)$ & $2.4(4)$ & $1.3(1)$ & $*$ & 0.300 \\
\hline Anorexia Nervosa & $0.4(2)$ & $0.5(1)$ & $0.0(0)$ & $*$ & 1.000 & $4.3(33)$ & $1.2(2)$ & $3.8(3)$ & $*$ & 0.153 \\
\hline Bulimia Nervosa & $0.2(1)$ & $0.0(0)$ & $0.0(0)$ & $*$ & 1.000 & 2.5 (19) & $3.6(6)$ & $2.5(2)$ & $*$ & 0.652 \\
\hline Schizophrenia & $0.2(1)$ & $0.0(0)$ & $0.0(0)$ & $*$ & 1.000 & $0.0(0)$ & $0.0(0)$ & $0.0(0)$ & $*$ & 1.000 \\
\hline $\begin{array}{l}\text { Attention Deficit } \\
\text { Hyperactivity } \\
\text { Disorder }\end{array}$ & $5.6(28)$ & $4.8(9)$ & $5.4(3)$ & $*$ & 0.964 & $2.8(22)$ & $2.4(4)$ & $3.8(3)$ & $*$ & 0.845 \\
\hline \multicolumn{11}{|l|}{ Results of the MIDI } \\
\hline $\begin{array}{l}\text { Intermittent } \\
\text { Explosive Disorder }\end{array}$ & $0.4(2)$ & $0.0(0)$ & $0.0(0)$ & $*$ & 1.000 & $0.3(2)$ & $0.6(1)$ & $0.0(0)$ & $*$ & .570 \\
\hline Compulsive Sexual & $3.2(15)$ & $1.7(3)$ & $3.6(2)$ & $*$ & .532 & $1.4(10)$ & $1.3(2)$ & $1.3(1)$ & $*$ & 1.000 \\
\hline
\end{tabular}




\begin{tabular}{|l|l|l|l|l|l|l|l|l|l|l|}
\hline Behavior & & & & & & & & & \\
\hline Compulsive Buying & $2.5(12)$ & $1.7(3)$ & $7.1(4)$ & $*$ & 0.102 & $3.9(29)$ & $6.1(10)$ & $5.1(4)$ & $*$ & 0.380 \\
\hline Kleptomania & $0.0(0)$ & $0.0(0)$ & $1.8(1)$ & $*$ & 0.079 & $0.0(0)$ & $0.0(0)$ & $0.0(0)$ & $*$ \\
\hline Trichotillomania & $0.4(2)_{\mathrm{a}}$ & $0.6(1)_{\mathrm{a}}$ & $5.4(3)_{\mathrm{b}}$ & $*$ & $0.009^{* *}$ & $1.6(12)$ & $1.9(3)$ & $2.5(2)$ & $*$ \\
\hline Gambling Disorder & $1.1(5)$ & $1.1(2)$ & $7.4(4)$ & $*$ & 0.013 & $0.3(2)$ & $0.0(0)$ & $0.0(0)$ & $*$ \\
\hline $\begin{array}{l}\text { Skin Picking } \\
\text { Disorder }\end{array}$ & $1.6(8)$ & $1.6(3)$ & $3.6(2)$ & $*$ & 0.407 & $5.4(41)$ & $9.0(15)$ & $5.1(4)$ & $*$ \\
\hline
\end{tabular}

Notes: All values are \% (n); *Fisher’s Exact Test; ${ }^{* *}$ Significant using Holm Sequentially Rejective Adjustment Abbreviations: MIDI: Minnesota Impulsive Disorders Interview.

For each pair of columns, the column proportions are compared using a $z$ test. If a pair of values is significantly different at the 0.05 level, the values have different subscript letters assigned to them. 
Table 5. Logistic Regression Analysis for BMI categories Predicting Reported Lifetime Diagnosis of Psychiatric Disorder by Males $(n=745)$ and Females $(n=1020)$, Controlling for Age

\begin{tabular}{|l|c|c|c|c|c|c|}
\hline & B & S.E. & Wald & Sig & Exp(B) & 95\% CI \\
\hline Males & & & & & & \\
\hline BMI normal (ref) & & & 13.815 & 0.001 & & \\
\hline BMI overweight & -0.312 & 0.235 & 1.763 & 0.184 & 0.732 & $0.461-1.160$ \\
\hline BMI obese & 0.939 & 0.303 & 9.588 & 0.002 & 2.557 & $1.411-4.633$ \\
\hline Age & 0.078 & 0.022 & 12.724 & 0.000 & 1.082 & $1.036-1.129$ \\
\hline Constant & -3.224 & 0.510 & 40.002 & 0.000 & 0.040 & \\
\hline \multicolumn{7}{|l|}{} \\
\hline Females & & 4.222 & 0.121 & & \\
\hline BMI normal (ref) & \multicolumn{7}{|l|}{} & & & & \\
\hline BMI overweight & 0.259 & 0.182 & 2.010 & 0.156 & 1.295 & $0.906-1.852$ \\
\hline BMI obese & 0.413 & 0.246 & 2.825 & 0.093 & 1.511 & $0.934-2.446$ \\
\hline Age & 0.043 & 0.019 & 4.897 & 0.027 & 1.042 & $1.005-1.081$ \\
\hline Constant & -1.840 & 0.419 & 19.326 & 0.000 & 0.159 & \\
\hline
\end{tabular}

